\title{
PENGAYAAN SENJATA NUKLIR SEBAGAI MODAL EKONOMI KOREA UTARA
}

\author{
Darynaufal Mulyaman ${ }^{1}$, Theofilus Jose Setiawan², \\ Jain T.A. Komboy ${ }^{3}$, Maria A.F.G Sukmaniara ${ }^{4}$ \\ 1 darynaufal.mulyaman@uki.ac.id,2theosetiawan07@gmail.com, \\ 3komboyjain@gmail.com, ${ }^{4}$ mariasukmaniara@gmail.com \\ Universitas Kristen Indonesia, Jakarta-Indonesia
}

\begin{abstract}
The purpose of the paper is to analyze North Korea's efforts to obtain economic capital through the enrichment of nuclear weapons amid the various sanctions imposed on it. This paper uses a constructivism approach in accordance in term of give arguments regarding North Korea's struggle to gain economic capital is an all-out struggle. Since the communist regime took control of North Korea, North and South Korea have continued to conflict to this day. Supported by the Soviet Union and aided by China during the Cold War era, North Korea was still able to survive. However, after the collapse of the Soviet Union and China's lack initiatives from helping North Korea, the North Korean economy worsened. In this paper, we found that North Korea used its nuclear capability as a bargaining chip to get what it wanted, especially for economic reasons.
\end{abstract}

Keywords: Constructivism, Political Economy, Capital, North Korea, Nuclear

\section{PENDAHULUAN}

Korea Utara adalah negara yang penuh dengan keunikan. Korea Utara merupakan sebuah negara di Asia Timur yang mengisolasi dirinya dari dunia luar sehingga mendapat sebutan sebagai The Hermit Kingdom (Schorn, 2006). Sembari menutup diri dari dunia luar, dalam sepanjang hidupnya Korea Utara mengalami berbagai masalah, salah satu masalah utamanya adalah masalah ekonomi. Korea Utara mengalami masalah ekonomi setelah keruntuhan Uni Soviet pada dekade 90-an. Sejak jatuhnya Uni Soviet, Korea Utara tidak lagi mendapatkan bantuan dari negara baru yang dibentuk, yaitu Rusia. Tiongkok juga tidak banyak membantu Korea Utara sejak jatuhnya Uni Soviet. Hal ini berdampak pada penurunan pendapatan negara yang dirasakan oleh Korea Utara seperti kekurangan pangan, kelaparan, kematian akibat kelaparan, dan masalah-masalah lain. Selain itu, menurut French 
(2014) Korea Utara juga mengalami keruntuhan industri, kebijakan pertanian yang gagal, kelaparan (famine), dan ketidakseimbangan tingkat pengeluaran militer yang terlalu tinggi. Pemerintah Korea Utara hanya mengandalkan ideologi Juche (self-reliance atau kemandirian) untuk dapat membangun dirinya sendiri melalui "jalan lain", yaitu memproduksi senjata nuklir.

Wacana Korea Utara untuk memiliki senjata nuklir tidak terjadi setelah berakhirnya Perang Dingin, tetapi sebelumnya. Hsieh dan $\mathrm{Hu}$ (2007) menyatakan bahwa keinginan memperoleh senjata nuklir dibuktikan dengan maraknya wacana pemerintah Korea Utara pada tahun 1980-an yang membahas pembangunan reaktor nuklir di Yongbyon. Reaktor nuklir ini diyakini memiliki kemampuan untuk membuat senjata nuklir. Hal ini tentunya menyebabkan negara-negara di sekitar Korea Utara yaitu Korea Selatan, Jepang, Rusia, Tiongkok, bahkan Amerika Serikat menjadi waspada. Namun, pada tahun 1994 telah terjadi kesepakatan bahwa Korea Utara akan berhenti membangun reaktor nuklir. Hsieh dan Hu (2007) juga menyatakan bahwa perjanjian ini ditandatangani oleh Korea Utara dengan Amerika Serikat dalam Perjanjian '1994 Agreed Framework'.

Hsieh dan $\mathrm{Hu}$ (2007) turut menjelaskan bahwa sebagai pengganti penutupan reaktor nuklir yang sedang dibangun, Amerika Serikat menyediakan 500.000 ton minyak per tahun kepada Korea Utara. Namun, kesepakatan ini tidak berlangsung lama. Pada tahun 2002, Korea Utara mengakui bahwa mereka diam-diam mengembangkan program senjata nuklir. Kemudian pada 9 Oktober 2006, sesuai laporan BBC (2017), Korea Utara melakukan uji coba ledak senjata nuklir bawah tanah di provinsi Utara Hamgyong, tepatnya di pusat uji coba nuklir Punggyeri. Uji coba nuklir ini kemudian dikecam oleh Dewan Keamanan Perserikatan Bangsa-Bangsa (DK PBB) dengan dikeluarkannya Resolusi 1718. DK PBB meminta agar Korea Utara segera kembali ke pembicaraan multilateral untuk mengakhiri uji coba nuklir (United Nations, 2006). Kecaman PBB tidak menghentikan Korea Utara untuk melakukan uji coba nuklir lagi. Hal ini dibuktikan dengan uji coba peledakan senjata nuklir bawah tanah kedua pada 25 April 2009. 
Menurut Nuclear Threat Initiatives (NTI) (2021) setidaknya, Korea Utara telah melakukan 6 kali uji coba senjata nuklir dari tahun 2006 hingga 2021.

Melihat adanya kecenderungan Korea Utara untuk memperkaya dirinya dengan senjata nuklir dan juga kecenderungannya untuk melakukan uji coba senjata nuklir, membuat Korea Utara dikenakan berbagai sanksi. Global Policy Forum (2020) menyatakan bahwa sanksi datang dari Uni Eropa, Dewan Keamanan PBB, Amerika Serikat, Tiongkok, Australia, Rusia, Jepang dan Korea Selatan. Kendati demikian, sanksi-sanksi tersebut tidak menyurutkan niat rezim Korea Utara untuk menghentikan rekayasa senjata nuklir, sehingga pertanyaan “Mengapa Korea Utara terus memproduksi senjata nuklir dan melakukan uji coba senjata nuklir sementara mendapat sanksi terus-menerus dari negara-negara lain?" sangat relevan untuk dibahas.

\section{Landasan Teori Konstruktivisme dalam Ekonomi Politik}

Menurut Theys (2017) Konstruktivisme melihat bahwa dunia tempat kita hidup saat ini adalah hasil dari konstruksi sosial. Konstruksi sosial telah menciptakan kondisi bagi masyarakat internasional. Interaksi antara negara dengan perwakilan negara yaitu para pemimpin negara tentunya akan menimbulkan berbagai macam pandangan yang berbeda terhadap negara lainnya. Sesuai dengan pemikiran Friedrich Kratochwil (1989), adanya unsur-unsur lain seperti norma, identitas, niat, dan bahasa merupakan bagian penting dari proses historis hubungan antar subjek. Oleh karena itu, Konstruktivisme melihat 'proses' dari sebuah "definisi". Menurut Kratochwil (1989) adanya ide, norma, identitas, niat, bahasa, media adalah hal-hal yang dapat mengkonstruksi pandangan. Selain itu, menurut Kratochwil (1989), dunia internasional lahir dari proses yang tidak hanya terjadi secara tibatiba, tetapi didukung oleh identitas, kepentingan, nilai, dan niat. Menurut logika ini, setiap negara pada akhirnya membentuk pola-pola tertentu hingga akhirnya suatu negara dapat dianggap sebagai teman dan musuh. Konstruktivisme turut mendapatkan dukungan dari pemikiran Nicolas Onuf.

Onuf (1989) percaya bahwa dunia adalah sesuatu yang kita buat sendiri yang diproses melalui simbol-simbol linguistik (bahasa), speech act, 
dan media. Ketakutan akan ancaman nyata dari senjata nuklir tidak muncul begitu saja secara tiba-tiba, tetapi melalui berbagai proses sehingga dapat dikatakan bahwa 'senjata nuklir adalah senjata yang berbahaya'. Dalam setiap variabel Konstruktivisme terdapat turunan, seperti simbol-simbol kebahasaan (linguistic symbol) yang menyatakan bahwa pembicaraan setiap representasi negara (aktor) yang dibicarakan dapat ditangkap oleh aktor lain dengan makna yang berbeda dan percakapan setiap aktor dapat membentuk dunia. Speech act, menurut Onuf (1989) adalah media konstruksi sosial sehingga simbol-simbol kebahasaan digunakan oleh aktor. Selain itu, penggunaan media adalah untuk mentransformasikan berbagai hal yang ada untuk dapat menguasai dan mendistribusikan informasi.

Konstruktivisme turut mendapat dukungan dari pemikiran Alexander Wendt. Wendt (1999) menyatakan bahwa dalam mendefinisikan suatu negara sebagai lawan atau teman dapat melalui tiga variabel, yaitu saling ketergantungan, nasib bersama, dan homogenitas. Menurut Wendt (1999), jika suatu negara tidak memiliki ketiga variabel tersebut, maka negara tersebut akan menjadi saingan bagi negara lain. Hal ini disebabkan tidak adanya konstruksi komunikasi yang lancar, kurangnya intensitas dari satu negara ke negara lain, dan kurangnya koherensi niat.

Pada analisis dasar konstruktivisme dan ekonomi politik menurut Balaam dan Dillman (2013) setidaknya terdapat empat hal yang harus diperhatikan. Pertama, gagasan, nilai, norma, identitas individu, kelompok, dan negara yang hadir dikarenakan adanya konstruksi secara sosial. Kedua, gagasan dan nilai merupakan kekuatan sosial yang sama pentingnya dengan faktor militer atau ekonomi. Ketiga, konflik dan kerja sama adalah hasil dari nilai dan keyakinan. Keempat, beberapa perubahan dalam politik internasional didorong oleh perubahan nilai dan keyakinan aktor dari waktu ke waktu.

\section{PEMBAHASAN}

\section{Pembangunan Ketakutan akan Senjata Nuklir}


Muller et al. (2013) menyatakan bahwa kepemilikan senjata nuklir, bersama dengan senjata biologi dan senjata kimia, adalah beberapa senjata yang akhirnya membuat PBB untuk menamakannya "senjata pemusnah massal" atau Weapon of Mass Destruction (WMD). Selama Perang Dingin, pengembangan senjata nuklir digunakan sebagai instrumen penyeimbang (deterrent) atau penangkal kekuatan militer. Amerika Serikat dan Uni Soviet memproduksi senjata nuklir, tetapi kedua negara ini tidak menggunakannya dalam perang terbuka. Jika kedua negara ini menggunakannya, maka hanya akan mencapai Mutually Assured Destruction (MAD). Meskipun bom nuklir tidak digunakan selama Perang Dingin, keberadaan bom nuklir di beberapa negara dapat memengaruhi berbagai aspek, seperti kebijakan nasional, keamanan regional, keamanan internasional, kerja sama internasional, dan lain-lainnya. Negara-negara pemilik senjata nuklir kemudian dipandang sebagai negara yang kuat karena memiliki pengaruh yang besar, baik kepada negara di dalam dan di luar kawasannya. Hal ini dikarenakan senjata nuklir dapat memengaruhi dan menunjukkan kekuatan negara.

Tidak diketahui secara tepat berapa jumlah senjata nuklir yang dimiliki oleh Korea Utara. Namun, menurut Arms Control Association (2020) diperkirakan Korea Utara memiliki sekitar 30 hingga 40 senjata nuklir. Korea Utara telah menunjukkan sifat agresifnya terhadap tetangganya dengan melakukan uji coba peledakan senjata nuklir dan peluncuran rudal berkapabilitas nuklir. Clapper (2014) menjelaskan bahwa program senjata nuklir dan misil Korea Utara dapat menimbulkan ancaman serius bagi Amerika Serikat dan lingkungan keamanan di Asia Timur, kawasan yang memiliki populasi besar, militer, dan ekonomi terbesar di dunia. Tentu saja, senjata nuklir Korea Utara akan menjadi sumber ketegangan yang dapat terus bertumbuh akibat didorong oleh faktor politik dan militer di Korea Utara yang terus mengagungkan senjata nuklir.

Produksi senjata nuklir dan uji coba rudal terus menimbulkan kekhawatiran di kawasan Asia Timur. Namun, produksi nuklir yang dilakukan oleh Korea Utara bukan hanya untuk kepentingan keamanannya saja, melainkan senjata nuklir dapat menjadi cara bagi Korea Utara untuk 
mendapatkan apa yang ia perlukan agar rezimnya dapat bertahan hidup. Senjata nuklir pun turut dipakai oleh Korea Utara untuk berdiplomasi dengan negara tetangga. Hal inilah yang menjadikan Korea Utara meninggalkan berbagai perjanjian tentang pembatasan produksi senjata nuklir dan pengujian ICBM, seperti Agreed Framework 1994 dengan Amerika Serikat dan perjanjian Non-Proliferation Treaty pada 2003.

Menurut Cordesman et al. (2016), Korea Utara percaya bahwa dengan memiliki senjata pemusnah massal dan senjata nuklir, akan memberikan dirinya jalan untuk mencapai tujuannya menjadi 'negara yang kuat dan makmur' (Kangsongdaeguk) tanpa menyerah pada apa yang mereka anggap sebagai 'pengaruh asing'. Dengan keyakinan Kangsongdaeguk ditambah dengan Juche, Korea Utara akan terus mengekstraksi uranium untuk mendapatkan bahan utama senjata nuklir untuk mencapai negara yang kuat, makmur, dan mempertahankan kekuasaannya melalui demonstrasi kekuatan nuklir di Asia Timur dan dunia. Meskipun Korea Utara mengalami pelemahan ekonomi, Korea Utara tetap memperkuat persenjataan mereka. Hal ini pun tidak dapat dilihat sebelah mata saja. Jika Korea Utara, menurut Mikheev (2013), benar-benar memiliki keinginan untuk menggunakan senjata nuklir untuk melawan musuhnya, maka serangan dari Korea Utara tidak dapat diabaikan.

\section{Ekonomi Korea Utara}

Sistem ekonomi yang terpusat dan berbagai sanksi yang dijatuhkan kepada Korea Utara telah melemahkan ekonominya. Pada tahun 1995, dalam artikel Wolf dan Akrimov (2005), Kantor Statistik Korea Selatan memperkirakan bahwa Produk Domestik Bruto (PDB) Korea Selatan berkisar 22 kali lebih tinggi dari pada Korea Utara. Dari tahun 1996 hingga 2002, muncul perkiraan bahwa PDB Korea Selatan adalah 25 hingga 27 kali lebih tinggi dari pada Korea Utara. Wolf dan Akrimov (2005) turut menjelaskan bahwa Korea Utara memiliki tiga sumber ekonomi, yang pertama adalah sektor primer (pertanian, pertambangan, dan pabrik negara), sektor pertahanan, dan court economy. 
Pada sektor primer seperti pertanian, Korea Utara diyakini memiliki kekuatan untuk membudidayakan beberapa ternak, salah satunya dalam bidang perikanan. The Fish Site (2019) menyatakan bahwa Korea Utara memiliki tingkat pertumbuhan yang stabil bagi perkembangan ternak ikan, seperti ikan salmon, ikan pollock, ikan mas, dan ikan lele. Perikanan sendiri, sesuai yang dijelaskan oleh Berlinger (2020), merupakan salah satu komoditas yang penting, bahkan diperkirakan bahwa ekspor ikan Korea Utara ke RRT membawa keuntungan bagi Korea Utara sebesar \$300 juta. Menurut Sang-Hun (2020) salah satu produk yang paling menguntungkan Korea Utara adalah ekspor cumi-cumi. Selain dari pertanian, Korea Utara juga mendapatkan pemasukan dari industri pariwisata.

Sebagai negara yang mengisolasi diri, Korea Utara membawa rasa keingintahuan bagi masyarakat dunia luar. Yi et al. (2017) menjelaskan bahwa wisatawan dari Tiongkok merupakan penyumbang terbesar bagi industri pariwisata Korea Utara. Korea Utara menjadi destinasi bagi 230,000 wisatawan Tiongkok dan destinasi terpopuler pada peringkat ke 24. Untuk mengembangkan industri pariwisata, Yi et al. (2017) turut menjelaskan bahwa pemerintah Korea Utara memperbolehkan adanya investasi asing. Selain pertanian dan pariwisata, Korea Utara memiliki berbagai cara untuk mendapatkan pemasukan, salah satunya adalah pemasukan melalui court economy yang merupakan sektor ketiga dari sumber ekonomi Korea Utara.

Lebih lanjut lagi, court economy, menurut Oh dan Hassig (2000) dikatakan sebagai salah satu sumber yang dapat mengamankan sumber daya negara yang perdagangannya tidak dapat dipertanggungjawabkan atau tidak dicatat kepada birokrasi ekonomi. Sistem court economy adalah sistem yang mencari keuntungan melalui berbagai "pintu belakang" yang hanya diberikan kepada para elite, militer, dan pejabat elite partai yang menyediakan sumber daya penting dan tidak tercatat dalam birokrasi ekonomi. Wolf dan Akrimov (2005) turut menjelaskan bahwa sumber daya ini kemudian digunakan untuk mempertahankan kontrol dan loyalitas kepada kepemimpinan sehingga rezim Korea Utara dapat bertahan. Meskipun 
memiliki tiga sumber utama bagi pendapatan, Korea Utara tetap mengalami masalah terutama dalam bidang ekspor dan impornya akibat dari sanksi.

Kemudian, menurut Silberstein (2019) meski terkena sanksi ekonomi, pengembangan nuklir, dan ICBM, setidaknya perekonomian Korea Utara tidak sepenuhnya dalam keadaan menuju bencana. Namun, akibat dari berbagai sanksi, Korea Utara tidak mampu menjual barang ekspor terpentingnya, yaitu batu bara, bijih besi, dan sumber daya alam lainnya yang merupakan hasil dari sumber ekonomi kedua, yaitu pabrik negara. Adanya sanksi ekonomi juga mengakibatkan Korea Utara tidak dapat berdagang dengan Tiongkok. BBC (2017) menyatakan bahwa hal ini berdampak besar pada perekonomian Korea Utara karena Tiongkok merupakan penyumbang utama lebih dari 90\% perdagangan internasional Korea Utara. BBC (2017) turut menjelaskan bahwa perdagangan dengan Tiongkok turun pada tahun 2018 karena Korea Utara dikenai sanksi pada tahun 2017 akibat uji coba rudalnya. Bahkan, Tiongkok pun turut memberikan sanksi kepada Korea Utara setelah Korea Utara melakukan berbagai uji coba senjata nuklir. Menurut Miryanti dan Pridarita (2020), pemberian sanksi yang ditujukan kepada Korea Utara dari Tiongkok dengan pembatasan pasokan gas alam cair dan bahan bakar minyak, telah menunjukkan adanya ketidaksetujuan program nuklir Korea Utara oleh RRT. Hal ini turut memberikan jarak panjang bagi hubungan Korea Utara dan Tiongkok. Sanksi-sanksi ini telah disetujui oleh PBB dan negara-negara tetangga Korea Utara sehingga merugikan Korea Utara sekitar \$1 miliar USD. Namun, Korea Utara juga dapat mendapatkan uang dengan cara lain, yaitu dengan perilaku rent seeking-nya.

Lalu, Wolf dan Akrimov (2005) menjelaskan bahwa Korea Utara memfokuskan dirinya dan bergantung pada keuntungan perjanjian dengan negara lain. Sikap rent-seeking ini tidak hanya menjadi sumber produktif, tetapi juga dapat dimanfaatkan oleh Korea Utara dalam melaksanakan kebijakan, ancaman, dan negosiasinya dengan negara lain. Sikap rentseeking ini digunakan Korea Utara sebagai "janji” kepada dunia untuk tidak mengembangkan sikap agresif, seperti memperkaya senjata nuklir, 
membangun ICBM, menjual senjata nuklir, atau WMD lainnya. Wolf dan Akrimov (2005) turut menjelaskan bahwa dengan cara ini, negara lain dapat membayar sikap rent-seeking Korea Utara dengan bantuan finansial, bantuan asing, makanan, bahan bakar, atau bahkan pinjaman.

\section{Asal Usul, Kegunaan, dan Ekonomi Politik dari Senjata Nuklir}

Keinginan Korea Utara untuk memiliki senjata nuklir dapat dilihat dari berakhirnya Perang Korea dengan perjanjian gencatan senjata di Panmunjom. Song (1991) menjelaskan bahwa jika kesepakatan gencatan senjata tidak berakhir dengan baik, Presiden Eisenhower menyatakan ia akan menggunakan senjata nuklir untuk mendapatkan kesepakatan yang lebih baik. Dalam konteks Perang Dingin, Korea Utara mau tidak mau harus hidup dengan ancaman pembalasan senjata nuklir jika perang terbuka dengan Korea Selatan terjadi lagi. Terlepas dari sentimen ketakutan akan perang, Song (1991) juga menjelaskan bahwa keinginan Korea Selatan untuk mengembangkan teknologi nuklir bagi kebutuhan komersial turut menjadi salah satu pendorong bagi Korea Utara untuk mengembangkan program nuklir. Pada 1978, Korea Selatan mulai mengembangkan pembangkit listrik tenaga nuklir pertamanya di Kori. Jika Korea Utara ingin membangun pusat nuklir, maka Korea Utara harus mengeluarkan uang yang banyak karena pembangunan pusat nuklir merupakan proyek yang mahal. Maka itu, Korea Utara mengandalkan bantuan ekonomi dari China dan Uni Soviet. Akibat dari mengandalkan bantuan Uni Soviet dan Tiongkok, Korea Utara mengalami kemerosotan ekonomi setelah keruntuhan Uni Soviet dan penarikan diri Tiongkok. Meskipun begitu, Korea Utara tetap mengembangkan senjata nuklir.

Kepemilikan senjata nuklir dapat menjadi instrumen untuk mendapatkan kesepakatan dengan cepat tetapi penuh dengan risiko. Song (1991) turut menjelaskan bahwa dengan memiliki senjata nuklir, Korea Utara akan lebih mudah untuk melakukan tawar-menawar dan berdialog dengan cepat dengan Korea Selatan atau negara-negara Barat. Senjata nuklir dapat digunakan oleh Korea Utara sebagai instrumen strategis bagi dirinya sendiri ketika mereka mengalami keterpurukan ekonomi. Korea Utara yang sedang 
mengalami pelemahan ekonomi akibat sanksi yang dijatuhkan oleh negaranegara Barat, ditambah dengan isolasi diri selama bertahun-tahun, tetapi memiliki senjata nuklir, akan menciptakan kecenderungan untuk menggunakan senjata nuklir untuk mendapatkan apa yang diinginkannya. Menurut Hsieh dan Hu (2007) strategi ini merupakan hasil perhitungan yang digunakan oleh para pemikir strategis dan pemimpin Korea Utara yang dengan cermat menghitung keuntungan dan kerugian sebelum bertindak dengan cara tertentu mengingat bahwa AS juga hadir di Semenanjung Korea. Adanya campur tangan Amerika Serikat di Semenanjung Korea akan membawa beberapa "keuntungan" bagi Korea Utara jika Korea Utara bertindak strategis dengan menggunakan senjata nuklir. Dengan memiliki senjata nuklir, Korea Utara dapat memanggil negara tetangganya dan Amerika Serikat untuk dapat mengadakan pembicaraan tingkat tinggi yang membahas denuklirisasi.

Oleh karena itu, sejalan dengan apa yang dijelaskan sebelumnya, Avery dan Rinehart (2014) juga menjelaskan bahwa telah terdapat beberapa pembicaraan tingkat tinggi yang diadakan oleh Korea Utara dan beberapa negara tetangganya. Salah satu pembicaraan tingkat tinggi diadakan pada tahun 1990-an di bawah Presiden Bill Clinton. Pembicaraan yang dilakukan antara Kim Jong-il dan Presiden Clinton tetap berlanjut hingga tahun 2000an. Terjadi beberapa perubahan pembicaraan yang dikarenakan adanya perkembangan kebijakan luar negeri Amerika Serikat terhadap Korea Utara di bawah pemerintahan Bush. Menurut Snyder (2007) pemerintahan Bush memutuskan di awal krisis nuklir Korea Utara untuk mengejar format negosiasi multilateral yang melibatkan enam negara berdasarkan persepsinya sendiri melalui pengalaman pertemuan yang dilakukan di bawah pemerintahan Clinton. Avery dan Rinehart (2014) kembali menjelaskan bahwa pembicaraan yang beralih dari format bilateral ke format multilateral membawa negara-negara tetangga Korea Utara turut bergabung dalam pembahasan denuklirisasi Korea Utara.

Pembicaraan ini dinamakan Six-Party Talks yang terdiri dari Tiongkok, Jepang, Rusia, Korea Utara, Korea Selatan, dan Amerika Serikat. Beberapa 
negosiasi mencapai kesepakatan kunci yang menetapkan kesepakatan untuk memberikan bantuan kepada Korea Utara, salah satunya adalah bantuan keuangan. Avery dan Rinehart (2014) menjelaskan bahwa Korea Utara telah menjadi penerima lebih dari \$1 miliar bantuan AS hingga tahun 2009. Prospek negosiasi meredup setelah peluncuran rudal pada Desember 2012 dan uji coba nuklir ketiga pada Februari 2013 di bawah kepemimpinan Kim Jong-un. Avery dan Rinehart (2014) turut menjelaskan bahwa Korea Utara melakukan uji coba ini dikarenakan adanya sanksi baru dari PBB dan Korea Utara menanggapinya secara tajam dengan meningkatkan retorikanya menggunakan senjata nuklir dan mengambil sejumlah langkah provokatif.

Korea Utara tidak memiliki solusi yang mudah untuk masalahmasalahnya. Hsieh dan Hu (2007) menyatakan bahwa rakyat Korea Utara akan dihadapkan pada situasi nyata negara lain dan akan sadar akan kondisi negaranya yang mengerikan di mana pemerintah Korea Utara lebih "peduli" dengan kekuatan militer atas dasar kebijakan songun, juga dengan senjata nuklir yang terus diagungkan, dibandingkan dengan warga yang kelaparan jika pemerintah Korea Utara membuka pintu negaranya, meningkatkan perekonomian dan negara, serta kehidupan masyarakat. Hal ini menjadi dilema bagi pemerintah Korea Utara karena jika mereka membuka negaranya dan rakyatnya mengetahui situasi di dunia luar, Korea Utara akan kehilangan legitimasi rakyatnya sendiri. Apalagi salah satu cara untuk mendapatkan apa yang diinginkan Korea Utara dari negara lain adalah melalui senjata nuklir yang memiliki potensi serta kemampuan untuk menghancurkan negara lain sebagai alat tawar-menawar. Park (2012) menyatakan bahwa senjata nuklir adalah satu-satunya strategi bagi Korea Utara untuk mencapai apa yang diinginkannya dan merupakan strategi yang telah tersedia bagi Korea Utara.

\section{Ekonomi Politik dari Sanksi}

Penangguhan program nuklir Korea Utara dapat dilakukan melalui pengenaan sanksi. Sanksi dapat digunakan sebagai instrumen untuk memaksa perubahan perilaku Korea Utara. Frank (2006) menjelaskan bahwa secara historis Presiden AS, Woodrow Wilson, menyarankan agar penerapan 
sanksi dapat digunakan oleh Liga Bangsa-Bangsa untuk menjaga perdamaian dunia. Lalu, Gordon (1999) menyatakan bahwa Presiden Wilson menjelaskan bahwa sanksi adalah obat damai, diam, dan mematikan. Frank (2006) turut menjelaskan bahwa sanksi multilateral, komprehensif atau selektif, militer, ekonomi atau non-ekonomi adalah beberapa dari banyak bentuk sanksi.

Pada konteks masalah nuklir, sanksi ekonomi merupakan sanksi yang sering diarahkan untuk dapat mengubah perilaku Korea Utara. Frank (2006) turut menjelaskan bahwa sanksi tersebut dapat dilihat dalam beberapa hal, seperti tindakan yang dilakukan oleh negara (pengirim) terhadap negara lain (sasaran). Frank (2006) menjelaskan bahwa terdapat tiga tujuan dari pengenaan sanksi dan ketiga tujuan tersebut antara lain untuk tujuan keamanan nasional, tujuan kebijakan luar negeri, dan penyelesaian sengketa perdagangan dan investasi internasional. Negara pengirim sanksi adalah Amerika Serikat, negara-negara tetangga, DK PBB, dan organisasi supranasional, sedangkan negara sasarannya adalah Korea Utara.

Sejak percobaan peledakan nuklir bawah tanah, Korea Utara telah menerima sanksi berulang kali dari negara-negara Barat dan Asia-Pasifik. Salah satu sanksi tersebut adalah sanksi ekonomi. Pengenaan larangan ekspor barang, teknologi dan jasa yang berkaitan dengan senjata, serta barang mewah skala besar, telah berlaku sejak Dewan Keamanan PBB mengadopsi Resolusi 1718 (UN, 2006). Sanksi ekonomi ini menyebabkan larangan impor dan ekspor produk tertentu ke Korea Utara. Noland (2009) menjelaskan bahwa ketegangan nuklir yang sengaja diciptakan oleh Korea Utara saat uji coba senjata nuklir 2006 dan pengenaan sanksi kepadanya, diperkirakan akan meningkatkan risiko interaksi ekonomi dengan Korea Utara sehingga negara-negara yang berinteraksi dengan Korea Utara dapat menekan (hingga menghentikan) perdagangan.

Jika sanksi ekonomi yang dijatuhkan kepada Korea Utara bertujuan untuk menumbangkan rezim Korea Utara, maka keinginan agar rezim tersebut jatuh akan kecil. Hal ini juga tidak menutup kemungkinan atau membuat Korea Utara semakin sulit untuk mendapatkan pendanaan bagi 
pengayaan senjata nuklirnya. Frank (2006) menjelaskan bahwa negaranegara yang telah menerima berbagai macam sanksi dapat beradaptasi dengan sanksi-sanksi yang telah diberikan oleh negara lain. Bukti dari berhasilnya Korea Utara untuk beradaptasi adalah bahwa ia masih dapat memproduksi senjata nuklir, dan juga dengan dilakukannya berbagai parade militer yang menunjukkan adanya persenjataan baru dan uji coba rudal balistik. Menurut Shin dan Smith (2021) Korea Utara terus mengembangkan sistem senjatanya di tengah kebuntuan pembicaraan yang bertujuan untuk membongkar persenjataan nuklir dan rudal balistiknya dengan imbalan keringanan sanksi AS. Hal ini dibuktikan dengan peluncuran rudal balistik pada 15 September 2021.

Selanjutnya, Frank (2006) menjelaskan bahwa Korea Utara telah menerima sanksi lain karena tujuan negara-negara lain yang bertujuan untuk memperbaiki situasi hak asasi manusia di Korea Utara, memastikan perdamaian yang stabil di Semenanjung Korea, mencegah proliferasi senjata nuklir, dan mempersiapkan proses unifikasi yang lancar di masa depan. Bossuyt (2000) menjelaskan bahwa semua pihak yang berperan dalam menjatuhkan sanksi terhadap Korea Utara tentu memiliki tujuannya masingmasing. Sanksi dapat dikatakan sebagai jalan tengah dalam politik internasional.

Hal ini dapat digambarkan seperti 'menjatuhkan sanksi kepada pemerintah tetapi di saat yang bersamaan "melukai" orang yang tidak bersalah'. Frank (2006) menyatakan bahwa rasa sakit akibat sanksi terhadap Korea Utara dapat membuat rakyat melakukan perlawanan terhadap pemimpin mereka. Namun, karena adanya kontrol yang ketat dari pemerintah pusat yang berada di bawah kepemimpinan tiga pemimpin dinasti Kim dan pengkultusan pemimpin dan juga ideologi Juche, membuat masyarakat Korea Utara tidak berani melakukan perubahan bagi pemerintahannya. Lebih lanjut lagi, dibalik ketatnya kontrol pemerintah di Korea Utara, menurut Mulyaman (2020) Korea Utara sebenarnya berada pada situasi yang di ujung tombak, karena Covid-19, mahalnya nuklir, dan kelaparan. 


\section{KESIMPULAN}

Pengembangan senjata nuklir Korea Utara merupakan salah satu cara untuk mendapatkan apa yang diinginkannya. Jika diperhatikan dengan tingkah Korea Utara melalui beberapa kali menguji coba senjata nuklir hingga akhirnya diadakan pembicaraan tingkat tinggi, maka senjata nuklir adalah alat diplomasi bagi Korea Utara untuk melakukan hubungan dengan dunia luar. Jika Korea Utara menggunakan senjata nuklirnya untuk menyerang Korea Selatan, maka ini adalah jalan bunuh diri bagi Korea Utara. Korea Utara memang "secara diam-diam" mengembangkan senjata nuklir yang digunakan untuk menakut-nakuti negara lain dengan menggunakan strategi psikologis. Senjata nuklir pun juga telah menjadi cara Korea Utara untuk mendapatkan bantuan uang. Kekurangan hard currencies, pengenaan sanksi-sanksi dari negara-negara Barat dan beberapa negara Asia-Pasifik, larangan berdagang, dan lain-lain, telah membuat Korea Utara menggunakan senjata nuklir dan uji peledakan nuklir atau peluncuran rudal menjadi strategi bagi Korea Utara untuk mendapatkan uang.

Senjata nuklir telah digunakan sebagai alat diplomasi untuk mendapatkan modal ekonomi. Hal ini dapat dilihat sewaktu pembangunan pusat nuklir masih menjadi wacana dan ancaman dari Korea Utara pada tahun 1993 untuk membangun pusat nuklir telah memaksa Presiden Clinton membuka pembicaraan tingkat tinggi dengan Kim Il-sung. Pembicaraan ini kemudian berlanjut menjadi Six-Party Talks yang berisikan Tiongkok, Jepang, Rusia, Korea Utara, Korea Selatan, dan Amerika Serikat pada tahun 2000. Meskipun pembicaraan ini mencapai beberapa kesepakatan seperti bantuan kepada Korea Utara sebagai imbalan atas denuklirisasi, masalah besar masih hadir. Hal ini dibuktikan dengan melakukan uji coba senjata nuklir dan uji coba nuklir ketiga pada Februari 2013 oleh Korea Utara.

Korea Utara harus menggunakan metode lain untuk mendapatkan uang. Oleh karena itu, Korea Utara cenderung menciptakan perilaku mencari ketegangan melalui peledakan nuklir atau peluncuran ICBM. Dengan banyaknya sanksi yang telah dijatuhkan, kebijakan songun, pengeluaran belanja militer yang besar, dan produksi nuklir atau ICBM yang tidak murah, 
membuat Korea Utara berjuang mempertahankan kekuasaannya. Ancaman nuklir Korea Utara semakin menjadi-jadi dari tahun ke tahun. Pembangunan kekuatan senjata nuklir oleh Korea Utara harus ditanggapi secara strategis oleh pemimpin-pemimpin dunia, terutama pemimpin-pemimpin negaranegara di Asia Timur. Hal ini dikarenakan senjata nuklir dapat menjadi ancaman pasti jika Korea Utara menggunakan senjata nuklirnya untuk menyerang negara lain.

Adanya ancaman untuk menggunakan senjata nuklir pada tahun 1953 jika AS tidak mendapatkan perjanjian yang tepat, keinginan Korea Selatan untuk memiliki pembangkit listrik tenaga nuklir bagi penggunaan komersial, hilangnya Uni Soviet dan mundurnya Tiongkok, ketakutan dari negaranegara Barat terutama balas dendam akibat Perang Korea, ketakutan Kim I1sung agar dua Korea tidak bersatu di luar ideologi Juche, kebutuhan akan hard currencies, tekanan sanksi-sanksi yang didapatkan dari berbagai negara, dan berbagai masalah yang ia alami, merupakan berbagai hal yang telah mengonstruksi dan memproses akhirnya mengapa Korea Utara memperkaya senjata nuklir sebagai modal ekonomi. Keadaan Korea Utara dan senjata nuklirnya seperti permainan catur, di mana pemainnya adalah negara-negara besar yang memiliki kekuatan militer yang kuat dan jika salah langkah, keberadaan kawasan Asia Timur akan terancam dari peta politik internasional walaupun Korea Utara paham dengan situasi pelik yang dimilikinya, terlebih pada masa pandemi Covid-19.

\section{DAFTAR PUSTAKA}

Ahn, M. 2011. "What Is the Root Cause of the North Korean Nuclear Program?” Asian Affairs, 38(4), 175-187. Diakses pada 1 Juni 2021. https://www.jstor.org/stable/23526518

Arms Control Association. 2020. "Nuclear Weapons: Who Has What at a Glance." Diakses pada 4 Juni 2021. https://www.armscontrol.org/factsheets/Nuclearweaponswhohaswha $\underline{t}$ 
Avery, Emma Chanlett dan Ian E. Reinhart. 2014. "North Korea: U.S. Relations, Nuclear Diplomacy, and Internal Situations.” Diakses pada 10 Juni 2021.

https://www.everycrsreport.com/files/20141205_R41259_6c1df0294 d1bf2865348bede886b9b051218608a.pdf

Balaam, David N., \& Dillman, Bradford. 2013. Introduction to International Political Economy. United Kingdom: Routledge.

BBC. 2017. "China imposes import bans on North Korean iron, coal and seafood." Diakes pada 9 Juni. https://www.bbc.com/news/business$\underline{40932427}$

BBC. 2017. "North Korea nuclear tests: What did they achieve?” Diakses pada 1 Juni 2021. https://www.bbc.com/news/world-asia-17823706

Berlinger, Joshua. 2020. "North Korea 'ghost ships' washed up in Japan because of China's 'dark' fishing fleet, NGO says.” Diakses pada 9 Juni 2021. https://edition.cnn.com/2020/07/23/asia/north-korea-ghostships-intl-hnk/index.html

Bossuyt, Marc J. 2000. "The adverse consequences of economic sanctions on the enjoyment of human rights." Diakses pada 8 Juni 2021. https://digitallibrary.un.org/record/419880

Clapper, James R. 2014. "Worldwide Threat Assessment of the US Intelligence Community. Senate Select Committee on Intelligence.” Diakses pada 4 Juni 2021. https://www.dni.gov/files/documents/Intelligence\%20Reports/2014 \%20WWTA\%20\%20SFR_SSCI_29_Jan.pdf

Cordesman, A., Ayers, C., \& Lin, A. 2016. "North Korean Nuclear Forces and the Threat of Weapons of Mass Destruction in Northeast Asia." Diakses pada 4 Juni 2021. https://www.csis.org/analysis/north-koreannuclear-forces-and-threat-weapons-mass-destruction-northeast-asia 
Frank, R. 2006. "THE POLITICAL ECONOMY OF SANCTIONS AGAINST NORTH KOREA.” Asian Perspective, 30(3), 5-36. Diakses pada 8 Juni 2021. https://www.jstor.org/stable/42704552

French, Paul. 2014. North Korea State of Paranoia. New York: Zed Books.

Global Policy Forum. 2020. Sanctions Against North Korea. Diakses pada 1 Juni 2021. https://archive.globalpolicy.org/security-council/index-ofcountries-on-the-security-council-agenda/north-korea.html

Gordon, J. 1999. "Economic Sanctions, Just War Doctrine, and the "Fearful Spectacle of the Civilian Dead". CrossCurrents, 49(3), 387-400. Diakses pada 8 Juni 2021. http://www.jstor.org/stable/24460472

Hsieh, J. F., \& Hu, X. 2007. "The North Korean Nuclear Crisis: An Introduction." Journal of Asian and African Studies, 42(3-4), 227-232. $\begin{array}{llll}\text { Diakses } & \text { pada } & 1 & \text { Juni }\end{array}$ https: / /journals.sagepub.com/doi/10.1177/0021909607076700

Kim, S. 1993. "Recent Economic Policies of North Korea: Analysis and Recommendations." Asian Survey, 33(9), 864-878. Diakses pada 9 Juni 2021. https://www.jstor.org/stable/i325260

Kratochwil, Friedrich V. 1989. Rules, Norms, and Decisions: On the Conditions of practical and Legal Reasoning in International Relations and Domestic Affairs. Cambridge: Cambridge University Press.

Mikheev, V. 2013. "The North Korean Nuclear Issue and The Northeast Asia Situation: Retrospect and Prospect." The Journal of East Asian Affairs, 27(1), 75-98. Diakses pada $17 \quad$ Juni 2021. https://www.jstor.org/stable/23595530

Miryanti, Renny, dan Gita Pridarita. 2020. "PERUBAHAN RESPON TIONGKOK TERHADAP UJI COBA NUKLIR KOREA UTARA (20132018)". Jurnal Dinamika Global 5 (02), 189-218. https://doi.org/10.36859/jdg.v5i02.196 
Mulyaman, Darynaufal. 2020. A Peculiar Case of North Korean Succession: What Should We Expect?. Diakses pada 4 Juni 2021. http://www.inadis.org/blog/2020/5/11/a-peculiar-case-of-northkorean-succession-what-should-we-expect

Müller, Harald., Aviv Melamud., and Anna Peczeli. 2013. "From Nuclear Weapons to WMD: The Development and Added Value of the WMD-Free Zone Concept." Diakses pada 4 Juni 2021. https://www.sipri.org/publications/2013/eu-non-proliferationpapers/nuclear-weapons-wmd-development-and-added-value-wmdfree-zone-concept

Noland, M. 2009. "The (Non-) Impact of UN Sanctions on North Korea." Asia Policy, (7), 61-88. Diakses pada 8 Juni 2021. https://www.jstor.org/stable/24904901

NTI. 2021. North Korea: Overview. Diakses pada 1 Juni 2021. https://www.nti.org/learn/countries/north-korea/

Oh, K.,\& Hassig, R. 2000. North Korea through the Looking Glass. Washington, D.C.: Brookings Institution Press.

Onuf, Nicholas. 1989. World of Our Making: Rules and Rule in Social Theory and International Relations. Columbia: University of South Carolina Press.

Park, Hans S. 2012. North Korea Demystified. Cambria Press

Sang-Hun, Choe. 2020. "Defying U.N. Ban, Chinese Ships Pay North Korea to Fish in Its Waters.” Diakses pada 9 Juni 2021. https://www.nytimes.com/2020/07/22/world/asia/north-koreasquid-sanctions-china.html

Schorn, Daniel. 2006. "North Korea: The Hermit Kingdom." Diakses pada 1 Juni 2021. https://www.cbsnews.com/news/north-korea-the-hermitkingdom/ 
Shin, Hyonhee, dan Josh Smith. 2021. "North and South Korea conduct missile tests as arms race heats up.” Diakses pada 16 September 2021. https://www.reuters.com/business/aerospace-defense/nkorea-firedunidentified-projectile-yonhap-citing-skorea-military-2021-09-15/

Silberstein, Benjamin Katzeff. 2019. "The true impact of North Korean Sanctions." Diakses pada 92021. https: / / www.eastasiaforum.org/2019/07/03/the-true-impact-ofnorth-korean-sanctions/

Snyder, Scott. 2007. "U.S.-North Korean Negotiating Behavior and the SixParty Talks." Dalam North Korea's Second Nuclear Crisis and Northeast Asian Security, diedit oleh Seung-Ho Joo dan Tae-Hwan Kwak. Hampshire: Ashgate.

Song, Y.S. 1991. "North Korea's nuclear issue." Journal of Northeast Asian Studies 10, 61-81. Diakses pada 10 Juni 2021. https://link.springer.com/article/10.1007/BF03025074

The Fish Site. 2019. "North Korea: salmon farming's next superpower?". Diakses pada 9 Juni 2021. https://thefishsite.com/articles/couldnorth-korea-be-salmon-farmings-next-superpower

Theys, Sarina. 2017. "Constructivism.” Dalam International Relations Theory, diedit oleh McGlonchey, S., Walters, R., \& Scheinpflug, C, 36--41. Bristol: E-International Relations Publishing.

United Nations. 2006. "Security Council Condemns Nuclear Test by Democratic People's Republic of Korea, Unanimously Adopting Resolution 1718.” Diakses pada 1 Juni 2021. https://www.un.org/press/en/2006/sc8853.doc.htm

Wendt, A. 1999. Social Theory of International Politics. Cambridge: Cambridge University Press.

Wolf, C., \& Akrimov, K. 2005. "Size, Growth, and Structure of the North Korean Economy." Dalam North Korean Paradoxes: Circumstances, 
Costs, and Consequences of Korean Unification, 9-20. Santa Monica: RAND Corporation.

Yi, Sangchoul., Chang-mo Ma., dan InJoo Yoon. 2017. "A new paradigm for tourism development in North Korea". Travel and Tourism Research Association: Advancing Tourism Research Globally 12. https://scholarworks.umass.edu/ttra/2017/Academic_Papers_Visual $L$ 